\title{
Sucrose reinforcement thresholds for hungry, thirsty, and non-deprived rats'
}

ROBERT C. BECK AND VICKI THIS ELLIS

WAKE FOREST COLLEGE

Sucrose reinforcement thresholds were determined for bar pressing. Hungry $S$ s showed lower thresholds than non-deprived $S$ s and thirsty $S$ s did not prefer sucrose at all.

Hungry rats have lower sucrose thresholds than non-deprived rats (Campbell, 1958) and bar press at higher rates for sucrose reinforcements (Collier, 1964). Thirsty rats prefer sucrose to water in brief exposure tests (Beck et al, 1965) but bar press no more for sucrose than for water (Beck, 1963; Collier, 1964). In the present experiment rats bar pressed in alternating time intervals for 1 or the other of 2 different solutions (water vs. sucrose), compromising the usual 2-choice preference situation and the single stimulus reinforcement situation. The object was to examine the thirsty rat's behavior more carefully, comparing water deprivation with food deprivation and no-deprivation conditions.

\section{METHOD}

\section{Subjects}

The Ss were 9 male albino rats about 100 days old.

\section{Apparafus}

Three identical Skinner boxes, previously described (Beck, 1963) were used. A telegraph key lever inserted through the front panel of each was the bar. Next to each side wall in the front panel was a hole $1.5 \mathrm{in}$. by 2.0 in. leading to a minibox through the bottom of which a dipper could deliver about $0.1 \mathrm{ml}$ of fluid. On a given day 1 dipper delivered sucrose solution and the other delivered distilled water. In alternating 2-min. intervals 1 dipper operated on a VI-15" schedule and then the other. A light in the minibox signaled which dipper was functioning in a given interval.

\section{Procedure}

The Ss were extensively pretrained with water reinforcements while water deprived. Each was then tested while food deprived (FD), water deprived (WD) and non-deprived (ND) with each of 6 comparative (Co.) stimuli; $1 \%, 3 \%, 9 \%, 18 \%, 27 \%$ and $54 \%$ sucrose (weight/volume). Subgroups of $3 \mathrm{Ss}$ each were subjected to the 3 deprivation conditions in counterbalanced order, with complete threshold determinations made for each $\mathrm{S}$ under his particular deprivation condition at the time. The Ss were adapted to a $23.0-\mathrm{hr}$. food deprivation schedule, a 23.5-hr. water deprivation schedule or ad lib food and water for 5 days prior to the start of each threshold series. On the last 2 days of each adaptation to schedule the Ss bar pressed for $1 \%$ vs. $54 \%$ sucrose, the extremes of the Co. stimuli. Each series took 12 days, 2 consecutive days for each Co. stimulus (counter- balancing position). The order of the Co. stimuli within each series was randomly determined. On each day Ss bar pressed for 13 2-min. intervals on each dipper, but data from the 1st pair were not counted since Ss were learning the stimuli at this time.

\section{RESULTS}

The results were analyzed for both individual and group thresholds. Threshold functions are plotted in Fig. 1 and the threshold values summarized in Table 1.

Individual thresholds were determined for each $\mathrm{S}$ by the method of constant stimuli. For each Co. stimulus the percentage of the 24 paired intervals in which $\mathrm{S}$ bar pressed more for 1 stimulus than the other were calculated. Each threshold was then determined by linear interpolation as that concentration "preferred" in $75 \%$ of the pairs. A preference in 18 of 24 pairs is

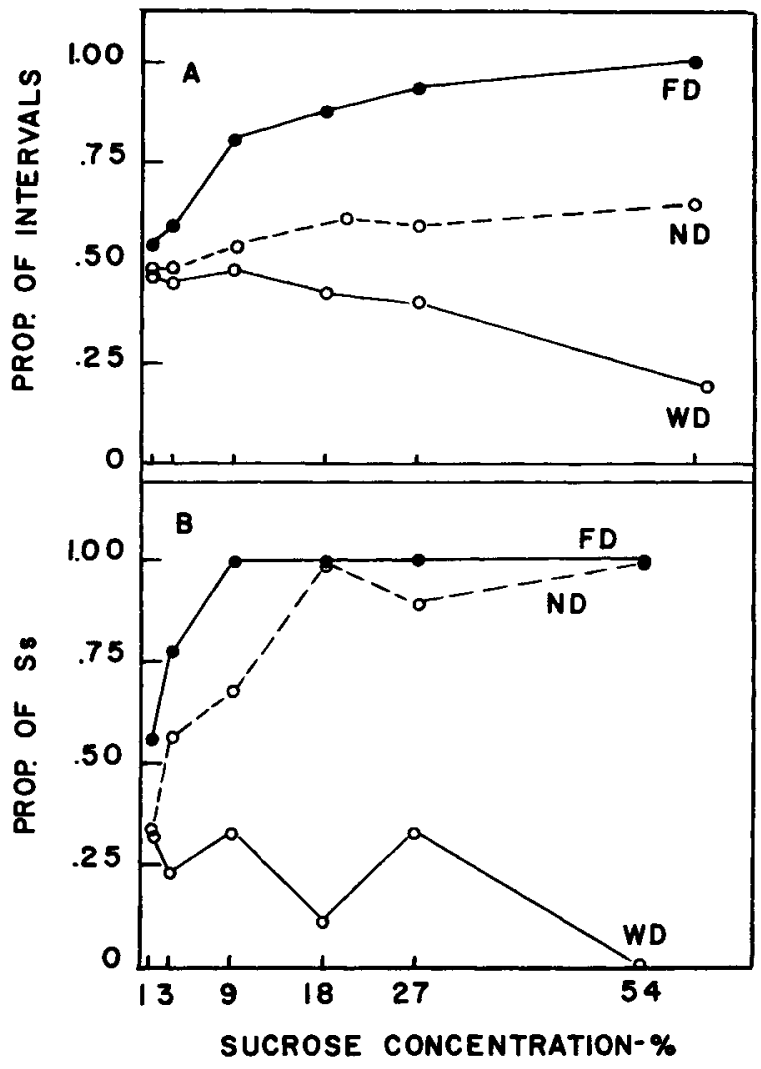

Fig. 1. Threshold functions for each deprivation condition. Panel $A$ is the mean percentage of paired intervals in which Ss responded more for sucrose than water. Panel $B$ is the percentage of Ss responding more for sucrose than water in their paired intervals. 
Table 1. Mean individual thresholds and group thresholds

\begin{tabular}{lccc}
$\begin{array}{c}\text { Threshold } \\
\text { Procedures }\end{array}$ & FD & \multicolumn{2}{c}{$\begin{array}{c}\text { Conditions } \\
\text { SD }\end{array}$} \\
& SUC $>\mathrm{HOH}$ & SUC $>\mathrm{HOH}$ & $\mathrm{HOH}>$ SUC \\
\hline Individual & $9.7 \%$ & $*---$ & $\star \star$ \\
Group (1) & $2.8 \%$ & $11.3 \%$ & $17.2 \%$ \\
Group (2) & $1.7 \%$ & $7.4 \%$ & $33.5 \%$ \\
\hline
\end{tabular}

* Only 3 Ss showed thresholds: $16.9 \%, 54 \%$ and $54 \%$

$\star \star 5$ Ss showed thresholds: $18 \%, 20.5 \%, 40.5 \%, 41 \%$, and $46.7 \%$

significant at the .01 level with a sign test. The functions are shown in Panel A of Fig. 1. Only under the FD condition did all Ss show a threshold value. Under WD, 5 of the 9 Ss showed a threshold for water over sucrose and no $\mathrm{S}$ showed a threshold under the ND condition.

Group Thresholds for the 9 Ss were determined in 2 ways. (1) They were estimated as the concentration where $75 \%$ of the Ss responded more for 1 stimulus than the other in more than half their 24 paired intervals. The functions are plotted in Panel B. Threshold values are considerably lower than found for individual thresholds. This is not surprising, of course, since a less stringent criterion was used. Thresholds were obtained for all conditions with this measure. (2) Group thresholds were also estimated as that concentration where $75 \%$ of the Ss gave more than $50 \%$ of their total responses for one stimulus over the other. The thresholds for the FD and ND conditions are lower here than for either of the previous two procedures (see Table 1). The threshold for the WD condition is higher than above, but this is due to minor variations enhanced by the small number of Ss.

\section{DISCUSSION}

The thresholds obtained here are considerably higher than those reported for 2-bottle preference tests (about $0.2 \%$ for hungry Ss, Campbell, 1958; about $0.4 \%$ for non-deprived, Burright \& Kappauf, 1963; Beck et al, 1965) but are in agreement that the thresholds are lower under food deprivation than non-deprivation. The absolute values of reinforcement thresholds may well be functions of such variables as size, frequency, and effort to obtain the reinforcements, as well as the exact method of calculation. This remains to be determined.
The fact that the Ss did not respond more for sucrose than water under the WD condition generally corroborates previous bar pressing results but leaves unexplained the $1.2 \%$ preference threshold for sucrose over water found by Beck et al. The present study was designed to produce a within-session contrast but, of course, was not identical to the 2-bottle situation where judicious selection from the tubes may provide a heightened contrast effect, mouth rinsing, or dilution, not possible even in the bar pressing situation used here.

Examination of the 1st or 2nd pair of intervals each day generally showed results consistent with the results for the whole session. For example, all the Ss hungry bar pressed more for $54 \%$ sucrose than water in the 1st pair of intervals (means of 27.9 and 7.8 responses). Such immediacy of differential reinforcing effects further indicates the importance of taste factors in the control of behavior. When hungry, sucrose is more acceptable and reinforcing to the rat; when thirsty, water increases in acceptability and reinforcing efficacy. The declining sucrose preference under the WD condition may also be partly due to post-ingestional osmotic effects since the decline begins to appear above $9 \%$ sucrose, the isotonic concentration. The results are generally consistent with hedonic theory (Young, 1961) and suggest that food and water deprivation differentially set some kind of biassing mechanism to alter the acceptability (and reinforcing functions) of water and sucrose solutions.

\section{References}

Beck, R. C. Effects of variations in water need and incentive concentration on bar-pressing. Psychol. Rep., 1963, 13, 31-37.

Beck, R. C., Self, J. L., \& Carter, D. J. Sucrose preference thresholds for satiated and water-deprived rats. Psychol. Rep., 1965, $16,901-905$.

Burright, E. R., \& Kappauf, W. E. Preference thresholds of the white rat for sucrose. J. comp. physiol. Psychol., 1963, 56, 171-173.

Campbell, B. A. Absolute and relative sucrose preference thresholds of the white rat for sucrose. J. comp. physiol. Psychol., $1958,51,795-800$.

Collier, G. Thirst as a determinant of reinforcement. In M. J. Wayner (Ed.), Thirst. New York: Pergamon, 1964.

Young, P. T. Motivation and emotion. New York: Wiley, 1961. Note

1. This research was supported by Grant No. HD-00937 from the National Institutes of Health and by the Research and Publication Fund of the Graduate Council of Wake Forest College. 